CONTRACT NUMBER: DE-A IO $1-93$ EH 89334

U.S. Department of Commerce

National Institute of Standards and Technology

(lonizing Radiation Division)

Report to the .

U. S. Transuranium and Uranium Registry

Richland, Washington

\title{
EXPERIMENTAL ASSESSMENT OF ABSORBED DOSE TO MINERALIZED BONE TISSUE FROM INTERNAL EMITTERS: \\ AN ELECTRON PARAMAGNETIC RESONANCE STUDY
}

\author{
Principal Investigator: \\ Marc F. Desrosiers \\ lonizing Radiation Division, 245/C229 \\ National institute of Standards and Technology \\ Gaithersburg, Maryland 20899 \\ telephone: $301-975-5639$ \\ telefax: $301-869-7682$
}

\section{SUMMARY}

EPR resonances attributable to radiation-induced centers in hydroxyapatite were not detectable in the bone samples supplied by the USTUR. These centers are the basis for imaging and dose assessment. Presumably. the short range of the alpha particles emitted precluded the formation of appreciable amounts of hydroxyapatite centers. However, one bone sample did offer a suggestion of hydroxyapatite centers and newly-developed methods to extract this information will be pursued.

\section{BACKGROUND INFORMATION}

Our approach was to assess the radiation dose to bone using a method based on electron paramagnetic resonance (EPR) spectrometry. EPR spectrometry is a quantitative physical method to measure paramagnetic centers produced by absorption of ionizing radiation. When ionizing radiations interact with mineralized bone tissue (hydroxyapatite), long-lived paramagnetic centers are produced in proportion to the absorbed dose. These centers have been used as a marker of radiation exposure and a measure of the absorbed dose in radiation-processed foods (Desrosiers, 1990), humans exposed both in radiation accidents (Desrosiers, 1991: Schauer et al., 1993) and to radiopharmaceuticals in medical therapy (Desrosiers ot al., 1991; 1993;

Desrosiers and Coursey, 1992).

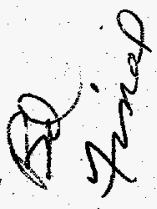


Other methods, such as autoradiography, measure the current distributions of radioisotopes. These radionuclides reflect the distribution and concentration at the time of measurement (usually post mortem), which may be many years after the exposure occurred. EPR is able to retrospectively measure the cumulative absorbed dose in the tissue. The bone mineral acts as a passive dosimeter and permanently stores a record of the absorbed dose. EPR is able to read this historical account of the radiation exposure. In essence, this approach is able to go back in time and provide information on the dose delivered. In some cases the measured dose includes that delivered by radionuclides which are no longer present, and for which there are limited or no data on the biological uptake and redistribution. The EPR dosimetry method offers the first direct experimental technique for measuring and mapping the absorbed dose in mineralized bone tissue.

The U.S. Transuranium and Uranium Registry provided NIST with bone samples for the EPR study. The primary goals were to examine the concentration (conventional EPR) and distribution (EPR imaging) of radiation-induced centers in the mineralized tissue, and calculate the bone depth-dose profiles of the radionuclides. From these data. a protocol for bone dose assessment measurements were to be drafted.

EPR. The EPR spectrum of the paramagnetic center in mineralized tissue of gammairradiated bone has an asymmetric shape due to a $g$-factor both perpendicular and parallel to the direction of the magnetic field (Figure 1B, 1C). Subsequent studies of irradiated calcified tissues attributed these centers to carbonate paramagnetic species (Bacquet et al., 1981).

The EPR spectrum of unirradiated bone tissue contains a single resonance commonly observed in all types of bone (Figure 1A). The nature of this resonance has not been determined, but it has been attributed to "organic radicals" (Caracelli et al. 1986). This signal is generally weak in intensity and is spectroscopically distinguishable from the hydroxyapatite radiation-induced signal (Figure 1B). The additional resonances upfield are identical to those prominent in Figure 1C. The endogenous "organic" EPR signal is not considered useful for dosimetry and does not interfere appreciably with the measurement of the hydroxyapatite signal for absorbed doses above 10 Gy.

\section{EXPERIMENTAL DATA}

Four different bone samples were prepared for measurement by cutting to an appropriate $\operatorname{size}$ (< $4 \mathrm{~m}$ in diameter) with a low-speed bone saw. These samples were then measured with our most sensitive EPR spectrometer (ESP 300 ) equipped with our most sensitive microwave resonator (TMH). The spectra for these four samples are shown in Figures 2-5. The dashed box encompassing the central part of the spectrum

\section{DISCLAIMER}

This report was prepared as an account of work sponsored by an agency of the United States Government. Neither the United States Government nor any agency thereof, nor any of their employees, makes any warranty, express or implied, or assumes any legal liability or responsibility for the accuracy, completeness, or usefulness of any information, apparatus, product, or process disclosed, or represents that its use would not infringe privately owned rights. Reference herein to any specific commercial product, process, or service by trade name, trademark, manufacturer, or otherwise does not necessarily constitute or imply its endorsement, recommendation, or favoring by the United States Government or any agency thereof. The views and opinions of authors expressed herein do not necessarily state or reflect those of the United States Government or any agency thereof. 
highlights the region in which the resonances for the organic and hydroxyapatite centers are calculated to appear. The shaded area is the region in which the hydroxyapatite should be apparent if present in high enough concentrations. In all of these spectra the most dominate feature is due to the organic center. In one case, a fragment from the ilium (03-551), a shoulder is observed overtapping with the organic signal at precisely the position calculated for the hydroxyapatite center. This observation suggests a low concentration of hydroxyapatite centers probably representative (and this is a guess based on my experience) of a maximum dose of a few Gy, but likely one Gy or less. We are developing a protocol for measuring bone irradiated to these low doses; it involves chemical removal of the organic component. In tests in this laboratory, this procedure was able to enhance measurement of the hydroxyapatite signal for bone irradiated to $10 \mathrm{~Gy}$. For bone irradiated to $1 \mathrm{~Gy}$, no signal was observed before treatment (due to the large signal from the organic radical): after treatment the hydroxyapatite was measurable and after re-irradiating with an additional dose of 1 Gy the signal approximately doubled. Therefore, the ilium sample is a good candidate for examination by this method.

Imaging. Spatial images of the distribution of paramagnetic centers induced by absorbed ionizing radiation in these bone samples were not possible due to the lack of signal in these bones. As an amendment to this report, a publication we are writing details how bone samples irradiated to 50 Gy with Co-60 photons, and electrons with energies of $2.5,1$, and $0.6 \mathrm{MeV}$ have been successfully imaged.

\section{CONCLUSION}

EPR resonances attributable to radiation-induced centers in hydroxyapatite were not detectable in the bone samples supplied by the USTUR. Since these centers are the basis for imaging and dose assessment, these tasks were not possible.

Presumably, the short range of the alpha particles emitted precluded the formation of appreciable amounts of hydroxyapatite centers. However, one bone sample did offer a suggestion of hydroxyapatite centers and newly-developed methods to extract this information will be pursued.

I would like to attempt additional experiments to determine the absorbed dose to the ilium sample (and possibly others if the treatment process proves useful). I request an additional one-year, no-cost extension to complete this project.

Marc F. Desrosiers Ph.D.

Research Chemist

Radiation Interactions \& Dosimetry Group 


\section{REFERENCES}

Bacquet $\mathrm{G}$. Troung VQ, Vignoles $\mathrm{M}$, Trombe JC, Bonel $\mathrm{G}$. ESR of $\mathrm{CO}_{2}^{-}$in X-irradiated tooth enamel and A-type carbonated apatite. Calcif. Tissue int. 33:105-109, 1981.

Caracelli I, Terrile MC, Mascarenhan S. Electron spin resonance dosimetric properties of bone. Heakh Phys 50:259-263, 1986.

Desrosiers MF. Assessing radiation dose to food. Nature 345: 485, 1990.

Desrosiers MF. In vivo assessment of radiation exposure. Health Physics, 61:859-861. 1991.

Desrosiers MF, Coursey BM, Avila MJ, and Parks NJ. Radiation dose. Nature 349:287, 1991.

Desrosiers MF and Coursey BM. A new approach to radiopharmaceutical dose assessment. Proceedings of the Fifth International Symposium on Radiopharmaceutical Dosimetry Oak Ridge TN, DOE CONF-910529:57-65, 1992.

Desrosiers MF, Avila MJ, Schauer DA, Coursey BM, Parks NJ. Experimental validation of radiopharmaceutical absorbed dose to mineralized bone tissue. Appl. Radiat. Isot. 44:459-464, 1993.

Schauer DA, Coursey BM, Dick CE, McLaughlin WL, Puhl JM, Desrosiers MF, Jacobson AO. A Radiation Accident at an Industrial Accelerator Facility, Health Physics 65:131-140, 1993. 

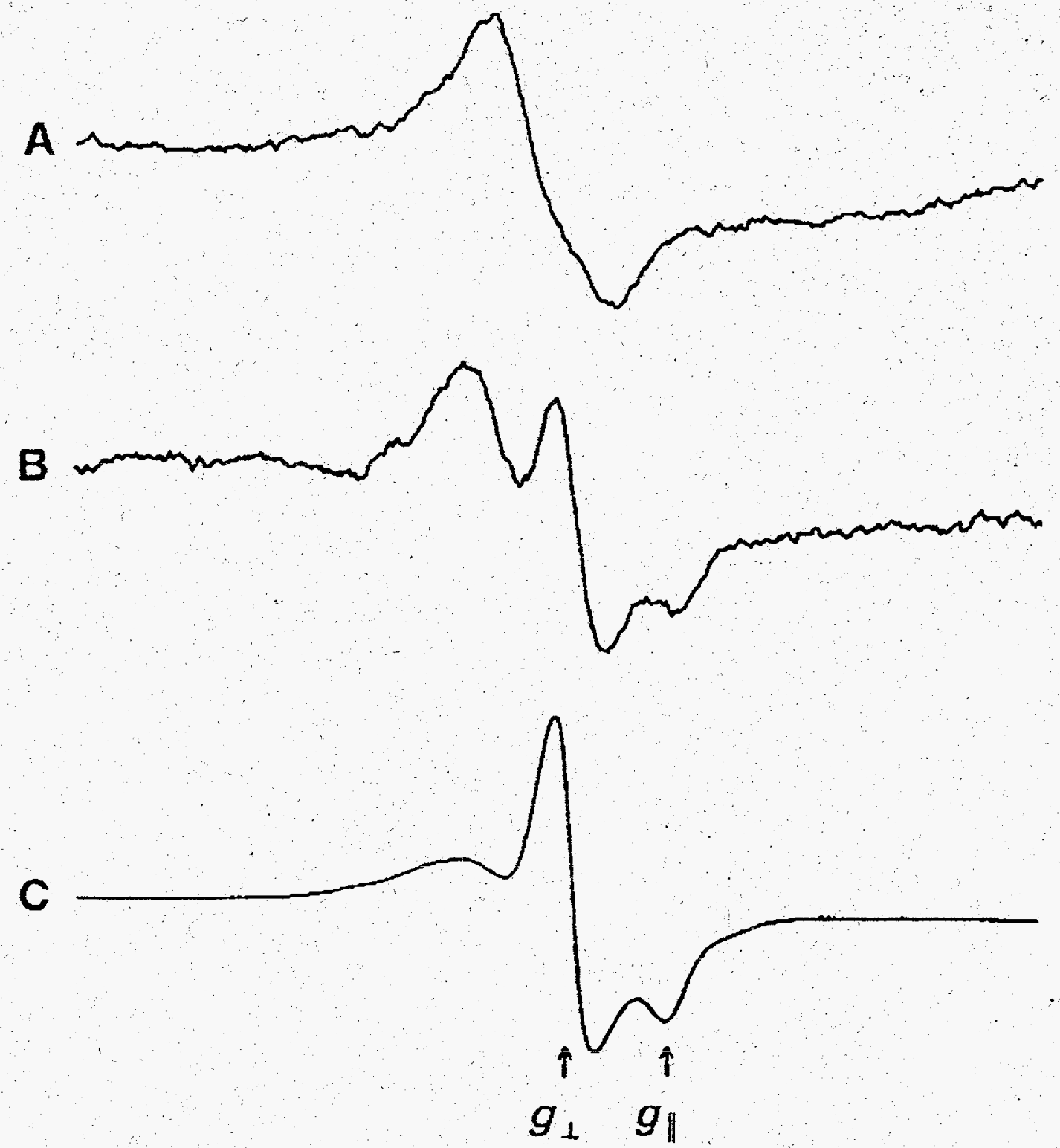

Figure 1. First derivative EPR spectra of: A) unirradiated bone; B) bone irradiated in vivo with Ho-166 (calculated dose $=30 \mathrm{~Gy}$ ); C) bone irradiated $>1000$ Gy with Cogamma rays. 


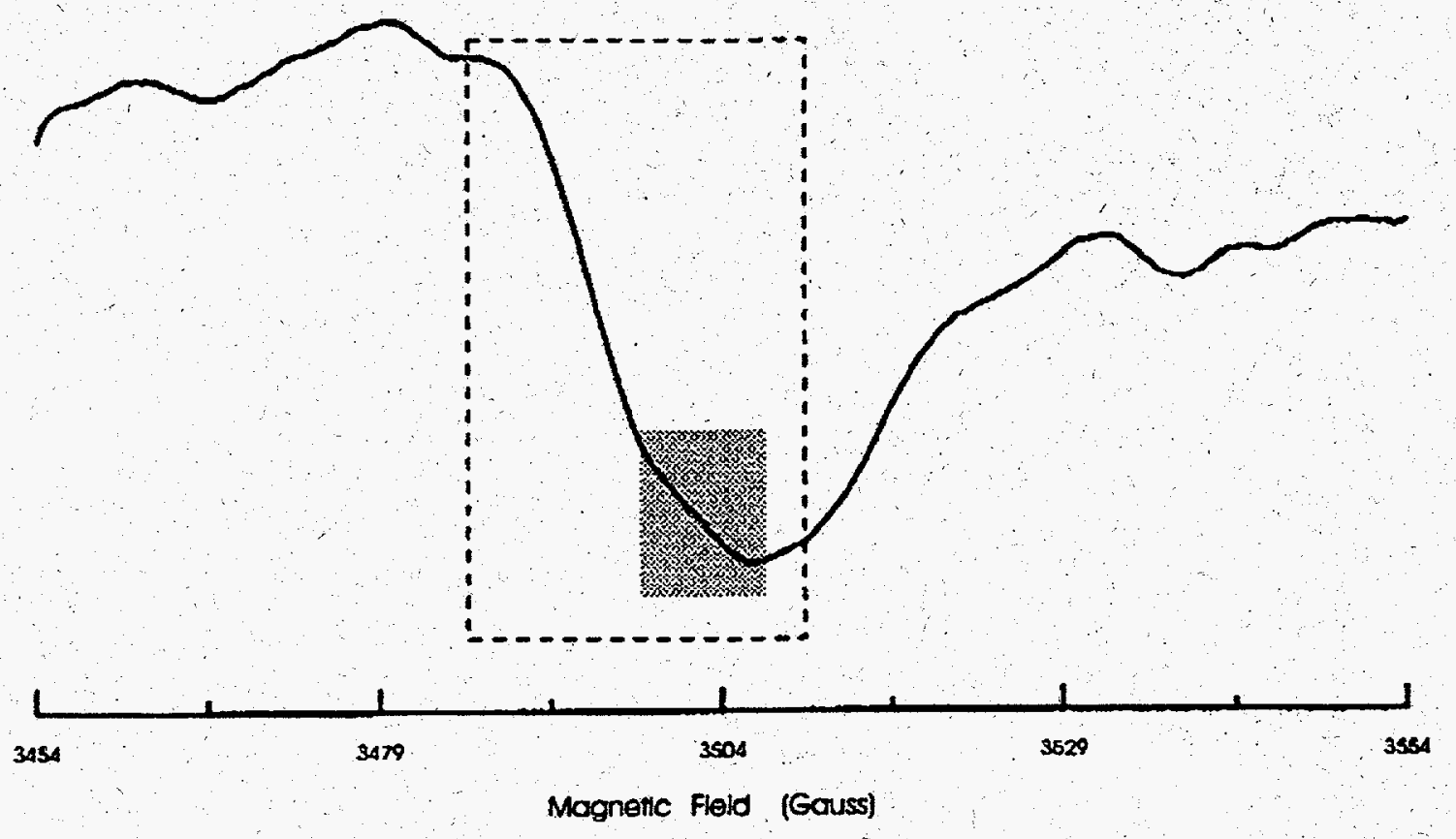

Figure 2. EPR spectrum of humerus cortical bone (USTUR \#03-551).

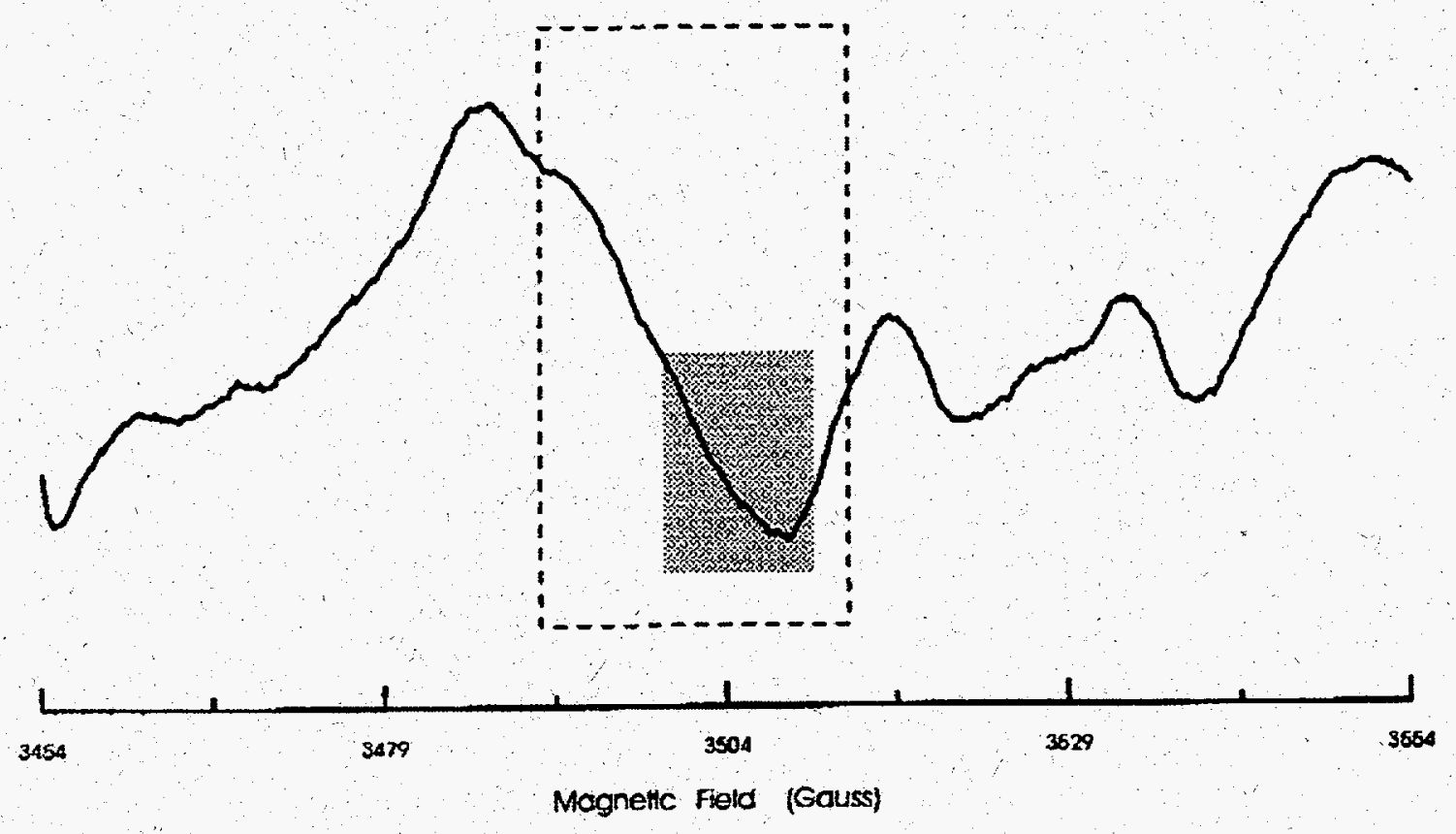

Figure 3. EPR spectrum of humerus trabecular bone (USTUR \#03-551). 


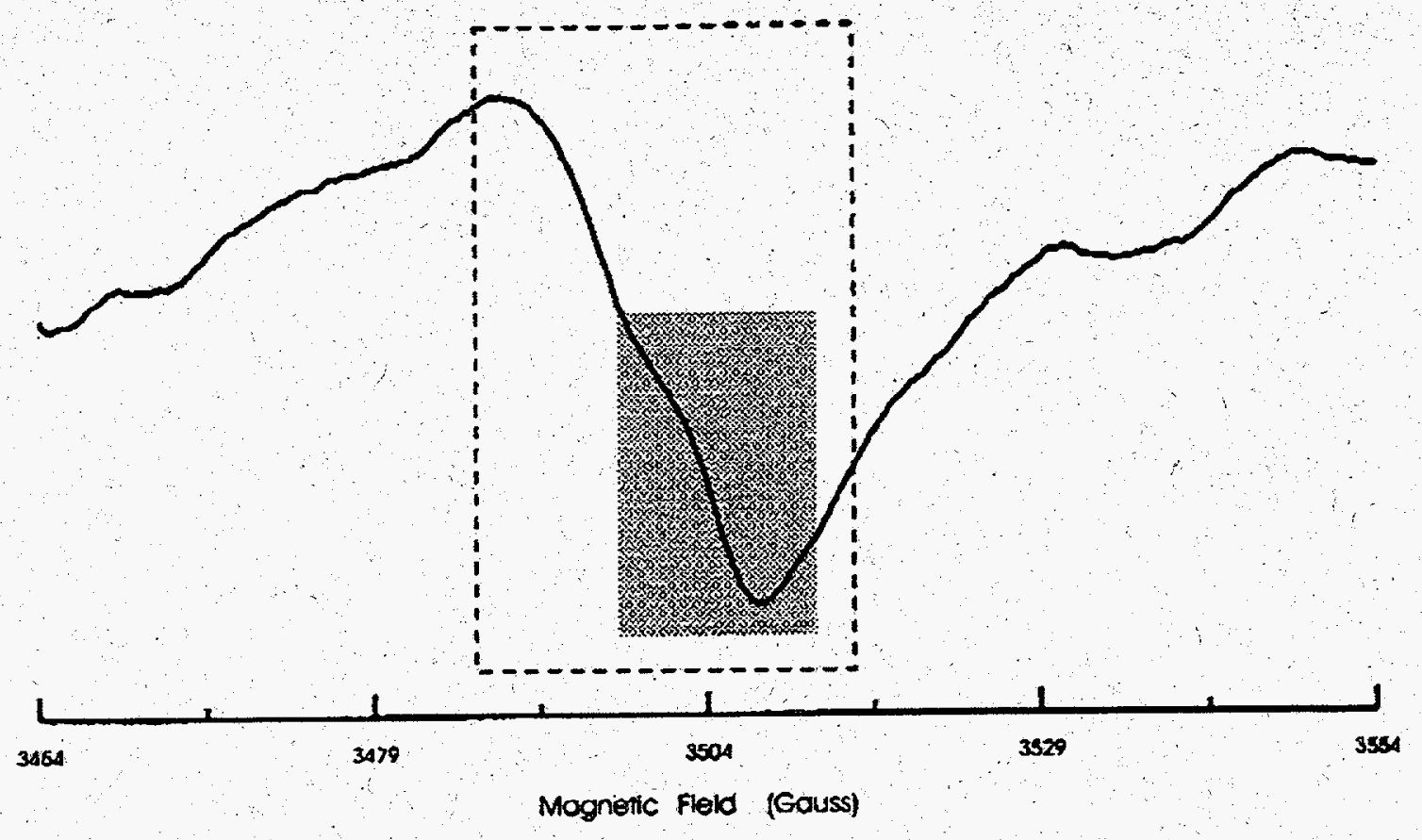

Figure 4. EPR spectrum of ilium bone (USTUR \#03-551).

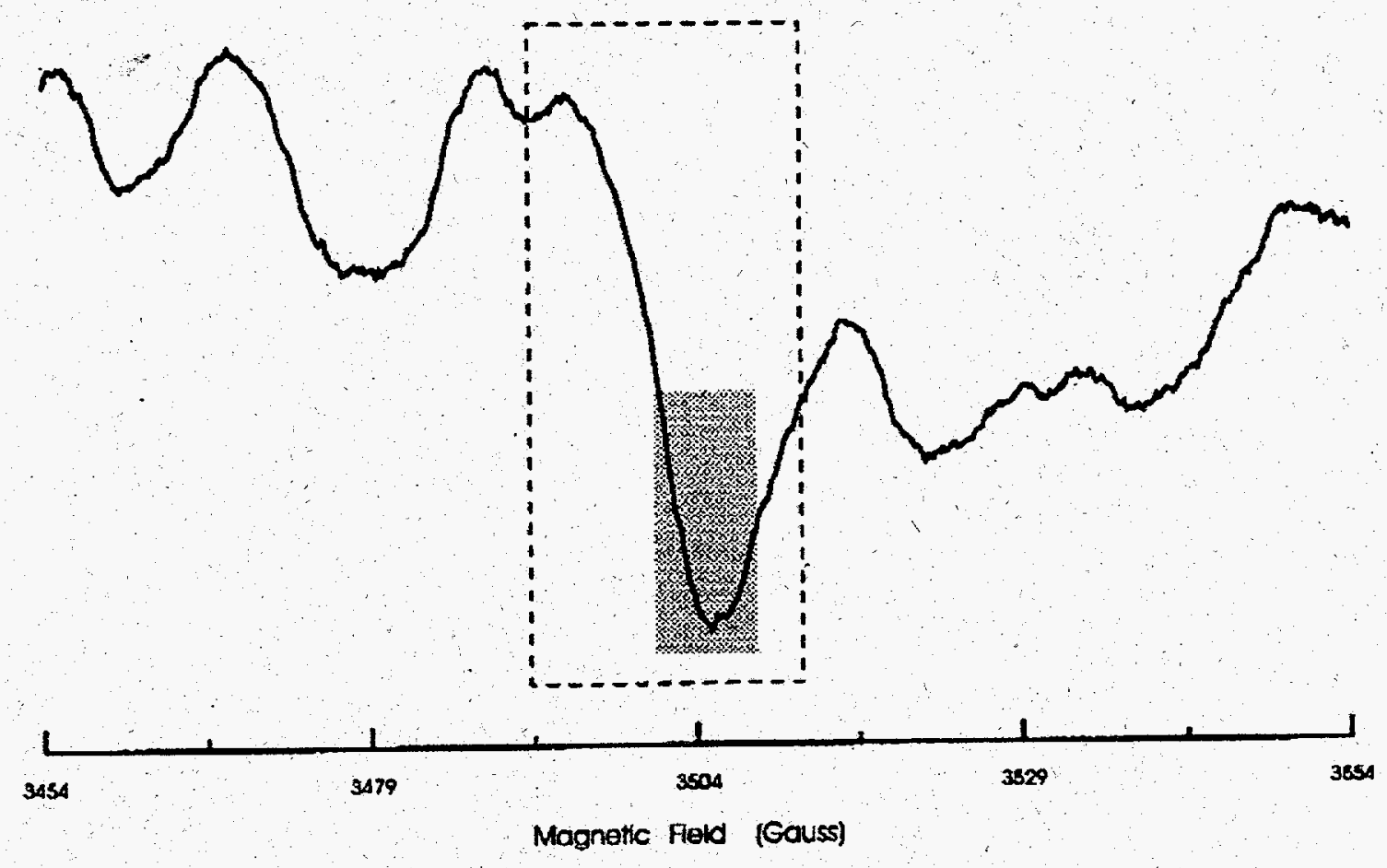

Figure 5. EPR spectrum of fibula bone (USTUR $\$ 05-958-K 8$ ). 